\title{
0 trabalho dos agentes comunitários de saúde em evidência: uma análise com foco na atividade'
}

The Job of Community Health Agents in evidence: an analysis under the perspective of the activity

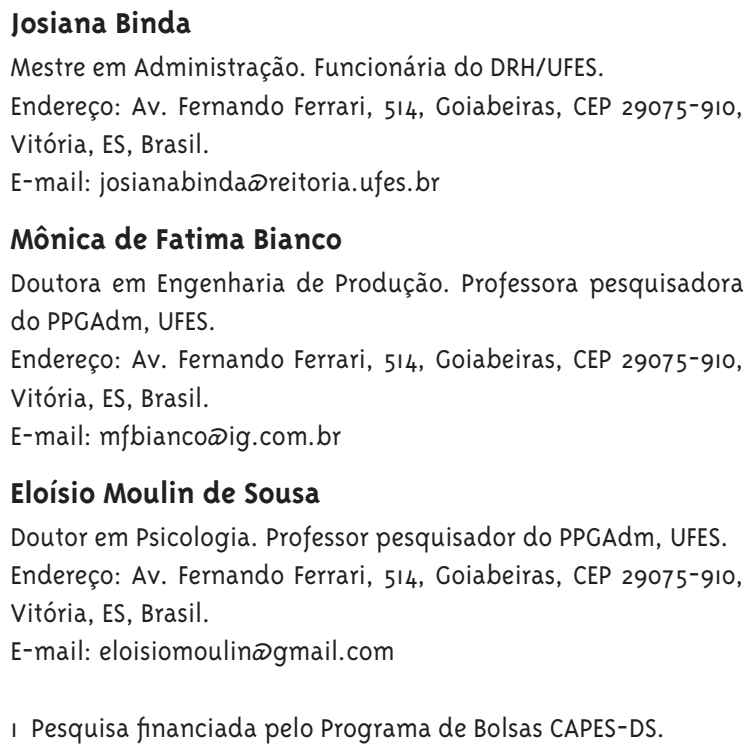

I Pesquisa financiada pelo Programa de Bolsas CAPES-DS.

\section{Resumo}

Esta pesquisa pretendeu fazer uma análise dos processos de trabalho dos Agentes Comunitários de Saúde (ACS) que atuam na Unidade de Saúde da Família (USF) Ilha das Caieiras, situada numa região periférica de uma capital do Sudeste do Brasil. Ela fornece serviços de saúde à população residente em um complexo de cinco bairros, cujo território abrange cerca de 2.30o famílias, sendo dividido em áreas, para atuação de uma Equipe de Saúde da Família e microáreas para atuação de cada ACS. Onze ACS que atuam na USF pesquisada têm seu trabalho prescrito conforme a concepção de gestão da Estratégia de Saúde da Família. Trata-se de uma pesquisa qualitativa em que se utilizou a analítica cartográfica de pesquisa, sendo esta apoiada na construção de diários de campo e na atividade. 0 trabalho dos ACS foi analisado sob o ponto de vista da atividade, com base no referencial teórico-analítico da Ergologia e da Ergonomia da Atividade. Pode-se afirmar que a construção social do território abrangido pela USF influencia sobremaneira o trabalho dos ACS e a produção de saúde da população. Há muitas variabilidades a serem geridas e, as condições de realização desse serviço são particularizadas pelo contexto socioeconômico, o que demanda "usos de si" no trabalho vivo e em atividade dos ACS.

Palavras-chave: Processos de trabalho; Saúde da família; Ergologia; Usos de si. 


\section{Abstract}

This paper analyzes the work methods of the Community Health Agents (ACS) that are involved in the Family Health Unity (USF) in Ilha das Caieiras, located in the outskirts of a capital in southeastern Brazil. The USF provides health care to a population resident in five neighborhoods, whose territory embraces about two thousand and three hundred families, divided in regions and smaller areas. Each region is under the responsibility of a Family Health Team, and each smaller area consists in the territory of a Community Health Agent (ACS). Eleven ACS that work in the researched USF had their work directives prescribed according to the conceptions of Family Health Strategy management. This paper presents a qualitative research that used a cartographic research analysis supported on daily field diaries and activity. The work of these professionals was analyzed under the perspective of the activity, based on the theoretical-analytical models of Ergology and Activity Ergonomics. It is legitimate to assert that the social construction of the territory under the USF's care greatly influences the work of the ACS and the production of the population's health. There is a lot of variability to be managed and the means for providing this service have particularities determined by the social-economic context, which requires different"uses of the self" at work and in ACS' activities.

Keywords: Work Analysis; Health Work; Family Health; Use of the self.

\section{Introdução}

A década que se iniciou em 1980 marcou um processo de grandes transformações no plano de organização político-econômico em âmbitos nacional e mundial. A crise econômica e o processo de (re) democratização em muitos países, dentre os quais o Brasil, estão no cerne do debate político que se instituiu pela redação do texto da Constituição Federal de 1988. Nele estão expressas mudanças das quais participaram, de alguma forma a sociedade civil (des)organizada. Da efervescência que o momento pós-década de 1980 provocou, faremos um recorte no campo da saúde para contextualizar nossa pesquisa.

Uma conquista importante que data dessa época é a criação do Sistema Único de Saúde (SUS), a qual marcou legalmente um debate no campo da gestão da saúde pública no Brasil, que, iniciado há algum tempo ganhou força na década de 1970 com a Reforma Sanitária. A criação do SUS dá-se efetivamente em 1990, mas muitas variáveis envolvem a afirmação e operacionalização dos seus princípios. 0 modelo centrado na assistência médica fragmentada e especializada, que considera o hospital como seu lugar principal de ação e não se articula com outras práticas terapêuticas ou racionalidades não médicas não apresentava mais perspectivas de atendimento às demandas de saúde da população.

Novas estratégias governamentais em alternativa ao modelo em questão foram se desenvolvendo, e, a partir de meados da década de 1990, o embrião do que hoje é a Estratégia de Saúde da Família (ESF) encontrava-se em gestação. Essa estratégia de gestão em saúde encontrou resistência e sofreu momentos de inflexão, como o projeto da Reforma do Estado, implementado em algumas instâncias do poder público no início dos anos 2000.

Assim, este artigo pretende analisar os processos de trabalho dos Agentes Comunitários de Saúde (ACS), acompanhando a atuação dos profissionais inseridos numa Unidade de Saúde da Família (USF), Ilha das Caieiras, que trabalham levando à população práticas integradas de atenção à saúde. Sendo particularmente importantes nas comunidades como essa, mais distantes de hospitais e centros de tratamento. Todo esse movimento, tivemos o desafio de acompanhar à luz do referencial teórico- 
-analítico da Ergologia (Schwartz, 1995, 1998, 2000, 2003, 2004a, 2004b, 2004c, 2011, dentre outros) na perspectiva de análise de situações de trabalho, do trabalho vivo e em atividade e, orientados também pelos princípios da cartografia (Fonseca e Kirst, 2003; Rolnik, 2006), enquanto postura de pesquisa e meio para produção dos dados.

\section{0 trabalho enquanto categoria e sob o ponto de vista da atividade}

O trabalho é definido de forma geral como atividade pela qual o homem modifica o mundo (Japiassu e Marcondes, 1996).

Com Marx (1974), a noção de trabalho torna-se um valor social universal, pois para ele

O trabalho é um processo de que participam o homem e a natureza, processo em que o ser humano, com sua própria ação, impulsiona, regula e controla seu intercâmbio material com a natureza. [...] Atuando assim sobre a natureza externa e modificando-a, ao mesmo tempo modifica sua própria natureza. Desenvolve as potencialidades nela adormecidas e submete ao seu domínio o jogo das forças naturais (Marx, 1974, p. 202).

Ou seja, a visão de trabalho como um processo o coloca como algo que está em construção permanente nessa relação recíproca do homem com a natureza.

Na concepção de Antunes (2000), o trabalho se expressa por meio da relação de transformação da natureza pelo homem, como produtor de valores de uso, pois objetos naturais são transformados em coisas úteis. Entretanto, o trabalho é visto como um processo dialético, dotado de contradição, que se constitui por meio das "formas mais desenvolvidas da práxis social” (Antunes, 2000, p. 140).

Dejours (2003) entende que o trabalho desenvolve-se no mundo subjetivo, físico (objetivo) e social. Logo,

"O problema prático (isto é, advindo da razão prática ou da práxis) é que uma conduta racional implica sempre um compromisso e não pode proceder de outra forma, a não ser por um compromisso; na melhor das hipóteses, de um compromisso refletido, pesado, pensado. A "sabedoria prática” supõe, então, que a ação esteja ligada a uma decisão cuja racionalidade está subordinada à qualidade da deliberação que a precede" (Dejours, 2003, p. 70).

Isto é, o homem está sempre dividido "entre aquilo que ele quer e aquilo que ele pode, entre o que ele deseja e o que ele deve" (Dejours, 2003, p. 70). O que se reflete em todas as situações ordinárias, inclusive nas situações de trabalho.

Apesar de muito se discutir sobre a categoria trabalho, ainda não há convergência a respeito dessa categoria de estudos, pois segundo Terssac e Maggi (2004), a noção de trabalho varia em cada sociedade. Sendo que algumas reservam-na para atividades penosas ou para atividades que exigem apenas o saber-fazer técnico, ou seja, a habilidade de lidar com ferramentas. Enquanto em outras sociedades o trabalho abarca não somente as atividades físicas como também as intelectuais; o fato de pensar.

Na visão contemporânea de trabalho, seria esse o trabalho imaterial. Para Amorim (2009, p. 141), "a produção imaterial seria a constituição da própria subjetividade como forma útil de valorização do capital, quer dizer, inusitadamente, se a compararmos ao padrão de produção anterior [fordista], hoje a subjetividade operária mostrar-se-ia como substrato central da produção (como força produtiva central).

Assim, não podemos deixar de discutir as mudanças que o trabalho tem sofrido, em especial a partir dos anos 1980. Afirmam Schwartz e Durrive (2007) que a mudança da qual falamos existe, e pode ser percebida, com o crescimento do setor de serviço, das telecomunicações, das estratégias de educação e transmissão a distância e com as automatizações. Isso faz com que algumas formas clássicas de trabalho entrem em declínio. Porém, os autores alertam que as profecias sobre o fim do trabalho que datam da mesma época são infundadas, pois se algumas formas de trabalho entraram em declínio outras novas formas de trabalhar surgem.

Na produção desta pesquisa, pactuamos com Durrive (2001) princípios de superação das representações que herdamos do taylorismo, da separação entre os que pensam o trabalho dos que o executam. Buscamos também superar a ideia de trabalho, presente no senso comum, como sendo: (a) confundido com emprego; (b) confundido com tarefa; (c) produto de um indivíduo isolado; e (d) produto de um operador substituível. 
Afirmamos que trabalhar é decidir em meio a uma multidão de compromissos entre os ditados pelo corpo - corpo esse adestrado, cada um a sua maneira - em busca da solução de problemas. Trabalhar é também decidir em função da evolução de um meio no qual estamos inseridos - meio este histórico -, tendo que se distanciar e ao mesmo tempo se arriscar a uma leitura das prescrições e normas que nos são impostas. E trabalhar é ainda mobilizar recursos pessoais - às vezes íntimos e nem sempre conscientes - para fazer escolhas e gerir variabilidades em situações de trabalho. Para Guérin e colaboradores (2004), o trabalho só pode se realizar na existência da tríade: atividade, condições [de trabalho] e resultado da atividade.

Logo, o trabalho, por mais simples e repetitivo que possa parecer é um processo de acumulação e transmissão de uma habilidade profissional - de quem o executa - trazendo consigo uma história individual e coletiva que o tornam complexo, enigmático e parcialmente impossível de se antecipar (Leplat, 2004; Terssac e Maggi, 2004).

Para falar de trabalho sob o ponto de vista da atividade, tomamos esta como sendo um núcleo de renormalização. $\mathrm{O}$ desafio é que nós no dia a dia do trabalho estejamos sempre a singularizar as condições de trabalho, normalizando-o de novo. Assim, toda atividade é singular e se inscreve na complexidade de uma situação. Ela é, portanto, um retrabalho de normas e fonte de novos saberes que estão "em gestação" (Durrive, 2001; Schwartz, 2004a). Saberes esses, que estão presentes todos os dias na atividade laboral, ainda que nem sempre sejam formalizados, expressos e reconhecidos (Guérin e col., 2004).

Confrontar-se com o conceito de atividade é o mesmo que ultrapassar o muro da evidência, pois - a atividade se distingue daquilo que a antecipa e a cerca: a tarefa e as condições de realização da tarefa, o emprego e as condições do emprego;

- a atividade viva mobiliza sinergias infinitamente diversas entre muitos atores, porque trabalhar é forçosamente se inscrever num projeto coletivo a ser executado num dado momento;

- a atividade nunca é anônima, nunca é indiferente à pessoa que trabalha; é caracterizada de forma única e singular (Durrive, 2001, p. 77).
A apropriação do conceito de atividade como ponto de partida reconhece que não há nenhuma situação de trabalho que já não sinalize uma transformação (Schwartz e Durrive, 2007). Para os autores, a ideia de atividade é sempre um "fazer de outra forma" ou "trabalhar de outra forma".

\section{A Ergologia: introduzindo conceitos}

Para Schwartz e Durrive (2007), a Ergologia se mostra como um projeto de melhor conhecer, e, sobretudo intervir nas situações de trabalho com o objetivo de transformá-las. Segundo eles, a perspectiva e o olhar da Ergologia buscam fazer um constante vaivém entre o macro e o micro. 0 macro que é geral e prescrito pela sociedade - portanto, histórico - e o micro é infinitamente singular e, se passa no dia a dia de cada atividade de trabalho. A isso eles chamaram de aprendizagem permanente dos debates de normas e de valores que renovam indefinidamente a atividade: é o "desconforto intelectual" diante da fragilidade que o saber do especialista representa para dar conta da complexidade do trabalho em atividade. 0 princípio das normas antecedentes engloba e amplia o conceito de trabalho prescrito de origem na Ergonomia da Atividade (Alvarez e Telles, 2004). Tais normas são tudo aquilo que encaminha uma ação a uma direção concebida a priori (daí antecedentes). Schwartz (1995) aponta três aspectos que demonstram o caráter híbrido da noção de normas antecedentes: contemplam "restrições de execução hétero determinadas", compreendem construções históricas e são inseparáveis dos valores.

No que diz respeito ao primeiro aspecto das normas antecedentes que reitera seu caráter híbrido, há imposições do meio que frequentemente são identificadas como algo negativo, algo a ser evitado, o prescrito é, às vezes "assimilado à expressão de um dogmatismo científico amparado por um poder social" (Schwartz, 1995, p. 20). No entanto, o autor ressalta que o prescrito, ou melhor, as normas antecedentes, desempenham um papel fundamental na atividade de trabalho, uma vez que são responsáveis pela determinação dos parâmetros elementares e necessários para que o trabalho ocorra. Um segundo aspecto dessas normas antecedentes diz respeito à compreensão das normas antecedentes como construções históricas. 
Schwartz e Durrive (2007) afirmam que a dimensão prescrita é o resultado de um patrimônio conceitual, científico e cultural. Neste patrimônio, podemos identificar, dentre outros, "o nível técnico-científico atingido e a história sempre particular que conduziu a este nível, os saberes-fazer historicamente constituídos, as linguagens que os formalizam e que permitem sua expressão, os modos de vida que estruturam as relações ao tempo, ao espaço, à comunidade, etc." (Schwartz, 1995, p. 20).

Sendo o terceiro aspecto das normas antecedentes ligado aos valores que elas portam e que permeiam a organização do trabalho nas instituições e suas relações com o ambiente (Schwartz, 1995). 0 autor defende que normas são essenciais, mas, o que devemos analisar é que essas normas desempenham um papel que não é suficiente para a execução do trabalho, e aí entram os saberes da experiência do trabalhador. Este desempenha cada atividade de trabalho de forma diferenciada no plano do real.

Assim, podemos dizer que as normas antecedentes são constituídas por "aquisições da inteligência e da experiência coletiva - portanto mais ou menos recebidas como bens 'de todos'" (Schwartz, 1995, p. 20). Este patrimônio, verdadeira matéria-prima das situações de trabalho, é influenciado por escolhas socioeconômicas, que se representam sob a forma de objetivos, de decisões a respeito das condições e meios a serem empregados, além de dispositivos hierárquicos, de procedimentos de avaliação, entre outros.

Desta forma, as normas antecedentes possuem dimensão mais ampla se comparada à noção de trabalho prescrito. As normas antecedentes são permeadas por valores, cultura e ciência, em âmbito coletivo, social. Indo além, elas também contemplam os meios físicos (materiais e equipamentos) para desenvolver as atividades.

A partir da noção de valor, fica mais apreensível a seguinte colocação: "a atividade industriosa, como toda a atividade humana, contém uma arbitragem e por isto está relacionada a valores" (Schwartz, 2004a, p.148). A importância dessa noção para a análise ergológica reside na pluralidade dos valores e como eles ajudarão a modificar, ou não, a norma antecedente. A renormalização das normas antecedentes se dá quando há um desencontro entre aque- les valores que permeiam os valores da organização, a norma antecedente e os valores dos trabalhadores.

Para Schwartz e Durrive (2007), os valores atravessam o micro da atividade, assim como atravessam toda a sociedade. E é somente através do fazer que se tem acesso aos valores que cada trabalhador engaja no trabalho. São esses valores que farão com que o indivíduo enquanto trabalhador opte por determinada conduta; como a atividade de trabalho é repleta de escolhas, esses valores são constantemente requisitados. Assim, a análise da atividade está diretamente relacionada aos valores, e compreender a razão pela qual se optou por determinada conduta é o desafio a que a Ergologia se propõe (Schwartz, 2004a).

Esse caráter híbrido das normas antecedentes, conforme descrito, influencia para que ocorra sempre uma reinvenção local, de forma que "toda a atividade de trabalho é sempre mais ou menos uma 'dramática do uso de si', tomada entre essas normas antecedentes e a necessidade de se dar a si mesmo normas, aí onde as primeiras estão "inacabadas" (Schwartz, 2003, p. 5).

Esta última citação nos remete a outro conceito da Ergologia e de grande importância para este trabalho, definido pelo autor como dramática do uso de si. O termo "dramática" remete à ideia de drama, pois toda escolha feita pelos trabalhadores quando da realização de cada atividade de trabalho é como um drama, onde ali se apresenta um verdadeiro embate de normas e valores "escolhidos" pelo trabalhador (Schwartz e Durrive, 2007).

A ergologia concebe esses "usos de si" de duas formas: o uso de si por si e o uso de si pelos outros. 0 uso de si pelos outros é o uso que trata do indivíduo imerso nas normas sócio-econômico-produtivas e nas instruções operacionais preconcebidas e planejadas por outros (Schwartz, 200o). O uso de si por si é aquele uso que cada um faz de si mesmo em suas escolhas. Cada trabalhador se posiciona de uma maneira entre esses dois usos, e, entender as forças que os levam a ocupar esse lugar-não-lugar-entre-lugar é também um desafio a que a Ergologia se propõe. Logo, "o uso de si por si é o uso do seu corpo, da sua inteligência, da sua história, da sua sensibilidade, dos seus gostos" (Schwartz e Durrive, 2007, p. 70).

Se as normas não antecipam tudo, então traba- 
lhar é fazer escolhas, é arriscar, é fazer uso de si em função de coletivos não impostos. Dessa forma, podemos afirmar que não existe meramente execução, e sim uso: toda atividade, todo trabalho é sempre uso - uso de si por si, uso de si pelos outros. Reafirmando, o uso de si por si mesmo é a convocação que cada trabalhador faz para julgar, pensar e interpretar as normas que lhes são colocadas, sendo sempre objeto de debates e confrontos por parte de cada ser humano, recriando-as, normalizando-as de novo, criando novas normas que produzem condições de vida (Rosa, 2001; Durrive, 2011).

E a renormalização, quando aparece? Visto como o processo de retrabalho das normas antecedentes que acontece em todas as situações de trabalho, levando-se em consideração as variabilidades do meio, os trabalhadores devem sempre arbitrar e encontrar os meios para atingir (e às vezes para não atingir) os objetivos fixados. Ou seja, as normas antecedentes, jamais são suficientes para "dar conta" da situação presente, são retrabalhadas, ou colocadas à prova por um ser vivente, em busca de reconstruir seu meio em função do complexo de valores que local e singularmente é o seu (Schwartz, 1998, 2000, 2004a; Schwartz e Durrive, 2007).

Ainda relativo à renormalização, Schwartz (200o) critica a visão "rasa" da relação homem-trabalho, na qual ela termina por negar a capacidade do sujeito de renormalizar não apenas sua atividade, mas todos os aspectos do meio que lhe impõem determinada coerção. 0 autor prossegue combatendo a homogeneização dos sujeitos, que ocorre por meio dos infinitos "modelos" que tentam circunscrever uma massa uniforme de trabalhadores inertes. Nesse sentido, se a norma que é imprescindível para a realização do trabalho está do lado do prescrito (tarefa), a renormalização está do lado da atividade (Schwartz e Durrive. 2007).

O trabalho nunca é pura execução, pois o meio no qual é possível a sua realização é sempre infiel (Schwartz e Durrive, 2007). Ele jamais se repete exatamente de um dia para o outro ou de uma situação de trabalho para outra. Logo, gerir essa infidelidade, onde há um "vazio de normas" é que demanda o "uso de si”. Cada trabalhador tenta lidar com essa lacuna descrita à sua forma, com sua própria história, seus valores, uma vez que ele também não pode fazê-lo de forma padronizada. Dessa maneira, contribui para singularizar ainda mais o meio, acentuando sua variabilidade.

Diante do exposto, normas antecedentes, valor, dramáticas do uso de si e renormalização são conceitos que envolvem princípios fundamentais que a Ergologia propõe, estando estreitamente ligados uns aos outros e cuja compreensão nos auxilia a entender que trabalho é sempre gestão e escolha.

\section{A Estratégia de Saúde da Família (ESF): uma nova orientação na gestão da saúde}

Um processo de reorientação da atenção básica em saúde inicia-se a partir da segunda metade da década de 1990. O fortalecimento da atenção básica à saúde passa a ter lugar de destaque entre os programas e investimentos do Ministério da Saúde (MS), dentre os quais estava o até então denominado Programa de Saúde da Família (PSF).

Na proposta do PSF, a família passou a ser enfocada como unidade de ação programática de saúde, e não somente o indivíduo, sendo introduzida a noção de área de cobertura a ser contabilizada por família. Ainda, buscando reorganizar e fortalecer a atenção básica, tornando-a mais resolutiva, e com o propósito de estabelecer vínculos de compromisso e responsabilidade entre profissionais de saúde e a população, numa prática de saúde integral e participativa (Vianna e Dal Poz, 1998). Assim, “[...] configuravam-se no SUS dois modelos de assistência: o tradicional e o da família associado aos agentes, porém, com remuneração diferenciada para o segundo, de forma a pressionar sua expansão e adoção, de forma exclusiva, nas áreas de maior risco e junto às populações mais carentes" (Calado, 2002, p.28).

O PSF colaborou para o estabelecimento de alianças na política de saúde entre gestores locais, técnicos externos à área da saúde e associações da comunidade. Esta nova tríade foi considerada suficiente para neutralizar os opositores da estratégia (Vianna e Dal Poz, 1998).

A Saúde da Família passa a ser a estratégia priorizada pelo Ministério da Saúde para organizar a Atenção Básica e operar seus princípios 
fundamentais, a saber: integralidade, qualidade, equidade e participação social. Dessa forma, a ESF tem como principal desafio promover a reorientação das práticas e ações de saúde de forma integral e contínua, levando-as para mais perto da família e, com isso, buscando melhorar a qualidade de vida dos brasileiros. Algumas características de gestão da ESF são estabelecidas a partir da noção de território geográfico, a saber: (a) a Unidade Básica de Saúde da Família (UBSF) é responsável por um território onde vive um determinado número de famílias, cadastrado pela Equipe de Saúde da Família (EqSF); (b) a partir do cadastramento é possível um diagnóstico inicial de saúde da comunidade local; (c) as informações fornecidas pelo cadastramento e pelo diagnóstico de saúde possibilitam que a equipe identifique quais pessoas ou famílias necessitam de uma atenção especial; (d) a partir desta identificação, a equipe terá como priorizar as ações programáticas requeridas para o enfrentamento dos problemas diagnosticados; (e) a estratégia possibilita ainda a criação de um espaço privilegiado para se trabalhar com a incorporação de hábitos saudáveis, potencializando o enfoque da promoção e prevenção e o estabelecimento do vínculo entre o indivíduo e a equipe; (f) o trabalho realizado permite a identificação de problemas cuja resolução requer ações que ultrapassem o setor saúde, potencializando as parcerias (Brasil, 2001b).

Conforme prescrição, a ESF está estruturada a partir da USF agindo por meio de uma equipe multiprofissional, responsável por uma determinada população que varia de 2.400 a 4.500 pessoas e é formada por, no mínimo, um médico generalista, um enfermeiro, um auxiliar de enfermagem e 4 a 6 agentes comunitários de saúde (ACS) (Brasil, 2001a).

A EqSF trabalha no formato de dedicação integral à saúde da comunidade, consolidando o vínculo com o usuário, conhecendo sua residência, os membros de sua família, sua história de vida, saúde e doença. No PSF, a equipe é que constrói ações ativas, buscando os usuários ao invés de esperá-los chegar ao serviço de saúde e possibilitando a criação do vínculo afetivo entre as pessoas e a equipe. Na necessidade de encaminhamento dos pacientes para os especialistas ou hospitais, a EqSF continua responsável pelo acompanhamento das pessoas, estreitando tais vínculos afetivos (Brasil, 2001a).

Finalmente, a ESF tem ainda alguns princípios centrais: desenvolvimento de um novo processo de trabalho nos cuidados à saúde; envolvimento de profissionais que compõem a EqSF e agregamento progressivo de outros profissionais/equipe multiprofissional; adstrição de famílias vinculadas à USF; promoção de atendimento por médico de família com capacidade de resolver de 80 a $90 \%$ dos problemas de saúde; atenção integral à saúde dos indivíduos e das famílias e articulação do atendimento com a rede de serviços de saúde/ referência e contra-referência (Cordeiro, 200o).

São os ACS que percorrem os territórios geográficos visando à integração com a comunidade, acompanhando aspectos da qualidade de vida dos usuários, configurando os processos de trabalho, que são o foco da pesquisa para este artigo.

Durante a pesquisa, a USF Ilha das Caieiras contava com aproximadamente 1.200 famílias cadastradas, assistidas por três equipes multiprofissionais as quais atendiam às três áreas geográficas em que o território se dividia. As três grandes áreas se subdividiam em treze microáreas, e cada uma delas era o território de atuação de um único ACS. Como havia, no momento da pesquisa, apenas onze ACS em atividade, duas microáreas ficavam "descobertas" e a população ali residente era atendida informalmente por ACS de outras microáreas da USF, as quais todas eram mulheres.

\section{Aspectos analítico-metodológicos}

Com base nos princípios conceituais e epistemológicos da Ergologia, optamos pela abordagem qualitativa. Mais especificamente, pela cartografia como meio de construção da pesquisa, a qual oferece princípios que possibilitam acompanhar fenômenos que não são estanques tampouco predefinidos, mas têm caráter dinâmico e processual, no caso os processos de trabalho. Ou seja, que se constroem no coletivo e disparam no pesquisador e no objeto pesquisado dispositivos de produção de subjetividade (Rolnik, 2006).

O termo cartografia busca na geografia certas especificidades para criar relações diferentes entre territórios, como a ideia de mapa. Procura capturar 
intensidades, acompanhando as transformações ocorridas no terreno percorrido e a implicação do sujeito percebedor no mundo cartografado (Fonseca e Kirst, 2003).

Assim, a cartografia pretende capturar no tempo o instante em que ocorre o encontro dos movimentos do pesquisador com os movimentos do território da própria pesquisa. 0 que se registra nos diários de campo são os encontros ocorridos, pois o cartógrafo sabe que é impossível congelar um determinado objeto (sujeito da pesquisa) para se analisar sua natureza. Cartografar é seguir o movimento e a processualidade da própria vida, da pesquisa viva, que produz desvios ao invés de regras (Fonseca e Kirst, 2003).

O local escolhido para a pesquisa foi o território da Unidade de Saúde da Família Ilha das Caieiras, que compreende cinco bairros localizados numa região denominada "Grande São Pedro", na periferia de Vitória-ES. São eles: São Pedro I, II, IV, Comdusa e Ilha das Caieiras.

Concomitante à pesquisa documental, realizada para se compreender toda a prescrição do trabalho das ACS conforme já apresentado, propusemo-nos a acompanhar os ACS nas visitas domiciliares, totalizando cerca de noventa visitas. Acompanhamos, em dias diferentes, as três equipes de saúde da família e conversamos informalmente com outros dez profissionais dentro da USF, além das conversas informais com as onze ACS durante as visitas domiciliares. Tomamos notas em diários de campo, que entendemos ser um dispositivo indispensável para a prática cartográfica. Neles foram registradas não só as percepções sobre as atividades de trabalho, mas também todas as informações correlatas ao tema da pesquisa. Trata-se de um coletivo de dados preenchido com as impressões, sensações, informações e fatos captados e registrados em muitas páginas, normalmente preenchidas em isolamento, logo após os engendramentos no campo.

Realizamos onze entrevistas junto os ACS com um roteiro. Inicialmente as entrevistas foram planejadas para ocorrer na sala de reuniões com roteiro semiestruturado e com dispositivo de gravação, mas a dificuldade imposta pela realização das entrevistas - formais e gravadas, levou-nos a lançar mão do Grupo como dispositivo de produção de dados (Benevides de Barros, 2007).
As entrevistas passaram a ocorrer por meio de conversas, entre uma visita domiciliar e outra, nos becos e escadarias do percurso, e nos momentos dentro da USF onde aguardávamos alguma reunião com o grupo de profissionais de saúde ou com grupo de usuários dos serviços do sistema único de saúde.

Dessa forma, passamos a fazer reuniões em grupo com os ACS, quando discutíamos algumas questões que emergiam durante o processo de acompanhamento em visitas, domicílio a domicílio, e que nos pareciam caras à pesquisa; principalmente porque escapavam da prescrição do trabalho destas profissionais e permitiam colocar em reflexão até que ponto elas tinham noção da forma como de fato desempenhavam o seu trabalho; uma espécie de confronto entre as anotações da pesquisadora e as trabalhadoras em busca do compartilhamento de pontos de vista e dos saberes.

Por fim, a produção dos dados deu-se por meio do acompanhamento às ACS a cerca de noventa visitas domiciliares de rotina, às reuniões com grupos temáticos e no dia a dia da USF, durante a imersão por um período de nove meses consecutivos em campo, quase diariamente se dirigindo à USF e participando intensamente das atividades lá promovidas.

\section{Uma análise com base nas atividades de trabalho dos ACS}

Para a análise dos dados produzidos em campo, promovendo a leitura atenta de todo o material elaborado, trabalhamos a partir de cinco planos de análise, como denominamos as tradicionais categorias, quais sejam: as mudanças recentes trazem insegurança e perspectivas; alguns desafios e variabilidades que tornam o trabalho das ACS ainda mais complexo; a relação com o território, a relação com o coletivo de trabalho e outras renormalizações, dramáticas do uso de si e a gestão do trabalho. Além disso, para preservar a identificação das profissionais, os relatos serão indicados por meio de letras que identifiquem as suas falas.

\section{As mudanças recentes trazem insegurança $e$ perspectivas}

Houve uma recente alteração na relação contratual das ACS. Até o ano de 2006, era uma relação de 
prestação de serviço indireta ao órgão de saúde municipal e a partir de 2007 passou a ser uma relação contratual direta, com ingresso a partir de concurso público, o que produziu efeitos no trabalho das ACS.

Por exemplo, a mudança com o rigor da utilização do uniforme, as análises da situação mostram a capacidade das ACS de renormalizar não apenas sua atividade, mas os aspectos do meio que lhe impõem determinada coerção, conforme Schwartz (2000) nos alertava. Antes - quando era contrato com a Cáritas ${ }^{2}$ - segundo a ACS D,

"[...] podíamos usar calça jeans ou bermuda, ou mesmo saia no joelho. $E$ o mais importante, podíamos usar tênis ou sandália por causa do calor e dos morros". Recentemente, reitera ela "mandaram pra gente uniforme novo, muito quente, calça de um tecido grosso e uma botina que parece de pedreiro [...]".

Quando questionadas sobre a estratégia desenvolvida por elas em relação ao uniforme, a ACS B revela que "às vezes a gente vem pra Unidade com o uniforme, depois passa em casa, coloca o tênis e vai trabalhar. [...]".

0 trecho demonstra uma resistência às normas antecedentes e a produção de novas normas, em busca de produção de vida por parte dos trabalhadores (Schwartz, 2000; Durrive, 2011). Para as agentes, o uniforme não ajudava na realização das atividades, ao contrário, dificultava o uso do corpo na realização destas.

Outra mudança percebida pelos trabalhadores foi em relação à disponibilidade de recursos indispensáveis ao trabalho; como ilustração trazemos o filtro solar:

"antes era mais fácil, [...] se a gente precisava de filtro solar, a gente pedia, eles logo mandavam e a gente podia escolher a melhor marca [...].", ao falar do presente ela ressalta "agora [...] demora muito e sempre mandam coisa de qualidade inferior porque é mais barato". $\varepsilon$ a mesma ACS desabafa "a gente tem que cuidar da saúde da população, mas pra isso estamos prejudicando a nossa, [...] já tem ACS com a pele toda manchada." (ACS B).
Aqui vemos o distanciamento do poder decisório na gestão, sentido pelas trabalhadoras na passagem do informal, pedido direto a Cáritas para o formal, solicitação de "lista de materiais" para compras, via recursos públicos e suas exigências. As diferentes instâncias da normalização interferindo nas situações de trabalho (Schwartz, 200o), para as ACS que de fato não participaram efetivamente como voz no processo de alteração contratual, ficou a sensação de piora das condições de trabalho e de não poder intervir em aspectos que elas consideram importantes para a realização de sua atividade laboral.

\section{Alguns desafios e variabilidades que tornam o trabalho das ACS ainda mais complexo}

As atividades de trabalho das ACS são marcadas por um número considerável de normas antecedentes, de prescrições, atribuições e regulamentações concebidas para antecipar o maior número de situações presentes no dia a dia da realização do trabalho. Mas, conforme afirmam Schwartz e Durrive (2007), Durrive (2001), cada atividade de trabalho é marcada por singularidades que se apresentam como desafios aos trabalhadores.

Cada ACS deve visitar pelo menos uma vez por mês cada uma das famílias cadastradas no território que compreende a microárea sob sua responsabilidade. No entanto há os grupos considerados prioritários pelo MS que devem ser tratados de forma diferenciada pelas ACS. No território da USF Ilha das Caieiras, encontramos um número considerável de pessoas pertencentes ao grupo de Hipertensos, Diabéticos, Gestantes, Crianças, Idosos acamados e usuários do grupo de Saúde Mental que se colocavam como desafios para o trabalho em atividade das ACS que ali atuam.

Há desafios aos quais as ACS são lançadas frequentemente e que coloca as ACS num debate constante entre normas e valores em suas atividades de trabalho (Schwartz, 2004c) - é o caso das gestações, em especial as gestações em idade adolescente, que são em grande número na região. Essa configuração as faz renormalizar constantemente suas ativida-

2 A Cáritas Brasileira faz parte da Rede Caritas Internationalis, rede da Igreja Católica de atuação social com sede em Roma. Organismo da CNBB - Conferência Nacional dos Bispos do Brasil, foi criada em 1956 e é reconhecida como de utilidade pública federal. Criada com o objetivo de articular as ações sociais católicas, na década de 1990, fez a interface com o Estado quando da criação do PACS (Programa Agentes Comunitários de Saúde), pois, os agentes comunitários de saúde eram contratados pela Cáritas e prestavam serviço ao Estado (Cáritas, 2008) 
des, buscando evitar que as adolescentes se tornem mães. "Sempre que vemos meninas [...] fora da escola no horário de aula, nós avisamos às mães, porque [...] hoje estão aí soltas, amanhã estão grávidas”, diz a ACS B. Além dos aspectos ressaltados de norma e valores que regem as ações, vemos que aspectos previstos na ESF de estabelecimento de vínculos com a população (Viana e Dal Poz, 1998) também estabelecem outras formas de agir.

O índice de gravidez na adolescência na região é um dado preocupante; só no ano de 2007, segundo dados da SEMUS (Secretaria Municipal de Saúde), o número de adolescentes que se tornaram mães da região de São Pedro foi da ordem de 166 (A Gazeta, 26/06/2008). Priorizar o cuidado a estas gestantes é uma meta do MS e faz parte do trabalho das ACS, mas elas têm dificuldade em fazer as adolescentes entenderem a importância do pré-natal, e as mães delas também não incentivam, "a gente faz de tudo, [...] às vezes nós mesmas marcamos as consultas, mas elas não vão", diz a ACS A e é complementada pela ACS E "muitas vezes elas chegam até o parto sem ter feito uma consulta sequer, [...] não podemos obrigar o paciente [...]”.

Acompanhamos um caso marcante de uma jovem de 24 anos que estava em sua sexta gestação. A última gestação era de alto risco, como as anteriores e os três últimos filhos são considerados crianças de baixo peso. Segundo as ACS, esse caso não é exceção na região, em geral as adolescentes adquirem "status" ao se envolverem com esses rapazes que praticam atos ilícitos e garantem para ela e para os filhos um "bom futuro" no que diz respeito à segurança, alimentação, vestuário, etc. Em contrapartida esses rapazes garantem a perspectiva de sucessão com os filhos, em especial se forem meninos.

As dramáticas do uso de si nestes relatos são instigantes, pois como mães, irmãs e moradoras querem alertar e prevenir; como profissionais é necessário cuidar, mas nenhum desses papéis são vivenciados com sucesso. Alertam e, muitas vezes, não são ouvidas; tentam orientar, mas nem sempre são atendidas. Sentem-se de mão atadas e o debate de valores entre o individual - pré-natal como sinônimo de prevenção, e o social - engravidar é sinal de status, é inerente às atividades (Schwartz e Durrive, 2007; Schwartz, 2003).

\section{A relação com o território}

Se para as ACS da USF Ilha das Caieiras por um lado "é muito bom trabalhar perto de casa, perto da família e dos amigos, ver os filhos crescerem [...] como lembra a ACS A, por outro "todos sabem quem somos, onde moramos; então somos ACS $24 \mathrm{~h}$ por dia [...]. Não desligamos nunca do nosso trabalho" pondera ACS B. Uma característica desse trabalho aparece bem demarcada, o engajamento involuntário na atividade sem delimitação clara de tempo dedicado a ela, característica do imaterial nele contido (Amorim, 2009).

Mas essa moeda tem também outros lados. Um deles é a restrição para mudança de endereço por parte das ACS, que apareceu nesta pesquisa e foi abordado por Queirós e Lima (2012). Além disso, como lembra a ACS B, "sabemos demais sobre nossa área, sobre o que acontece ali, e sabemos demais sobre a vida das pessoas que vivem ali, isso nos dá medo e insegurança [...], nos sentimos ameaçadas por saber demais". Acompanhamos algumas situações que "dão vida" a essa fala, quando "subimos as escadarias" para ir até a microárea da parte mais alta dos bairros e nos percebemos acompanhadas por um homem, o qual se mantendo a uma distância mínima que nos permitisse "fazer o nosso trabalho", deixava claro que "ele estava por ali”. Após o retorno à USF, conversávamos sobre algumas situações e a ACS B afirmou "nós sabemos o que acontece ali, e eles sabem que nós sabemos, mas nós fingimos que não vimos nada [...], e assim continuamos o nosso trabalho". Nessa mesma microárea, onde ocorreram essas passagens aqui relatadas, havia transcorrido "um fato" que fez com que a ACS B ficasse por três meses sem visitar as residências por proibição de alguns moradores. Passagens como estas mostram a interferência da territorialidade no trabalho das ACS e, a inteligência mobilizada para saber trabalhar em tais contextos é aspecto da atividade industriosa (Schwartz, 1995). E, como dito por Schwartz (2011, p. 8) "todo sujeito, todo grupo humano no trabalho é um centro de vida, uma tentativa de apropriação do meio, e sua vida no trabalho não é uma cerca separada de sua ambição de vida global.”

São relatos da complexidade do trabalho. Se estas complexidades são conhecidas dos gestores públicos, também estes devem estar cientes das 
renormalizações necessárias, pois ficar três meses impedida de realizar o seu trabalho pelas ruas do morro somente é possível porque há renormalização do trabalho em outras instâncias, superiores, também. Outros profissionais não veem ou fingem não ver o que acontece para que a ACS em questão possa renormalizar o seu trabalho, tendo em vista as dificuldades e variabilidades colocadas pelo meio (Schwartz e Durrive, 2007; Durrive, 2011). Ou seja, diferentes facetas da importância da transversalidade do trabalho humano permeando os sistemas burocráticos são colocadas em evidência ao se analisar situações como essa, que no mínimo dão visibilidade a tolerâncias permitidas, porém não prescritas para o trabalho dos agentes públicos.

\section{A relação com o coletivo de trabalho}

Concordamos com nossos interlocutores, dentre eles, Schwartz e Durrive (2007), que todo trabalho é coletivo, ainda que alguns pareçam individuais ou se individualizem a partir de ações, indicadores de avaliação e metas; há sempre um coletivo presente em cada atividade individual. Há mais evidências disso quando se trabalha numa perspectiva de rede (Castells, 2007) como a saúde está estruturada hoje no Brasil e quando se trabalha em equipes multiprofissionais como é o caso das ACS. Analisemos algumas passagens que demonstram a força e a presença desse coletivo nos movimentos da pesquisa.

Fica explícita na fala a seguir, a distinção entre a forma como as ACS se percebem dentro dessa rede social de trabalho; o discurso dos gestores da área de saúde e a forma como os profissionais da USF as percebem.

"a Unidade só funciona por nossa causa [...] se não falarmos com enfermeiro, médico, psicólogo o que está acontecendo 'lá fora' eles só ficam sabendo sobre os pacientes que vêm aqui procurar ajuda [...]" (ACS D).

Em contrapartida, percebemos em algumas reuniões com grupos de usuários e, principalmente, com o grupo de profissionais da USF que os outros profissionais, mesmo membros das equipes de saúde não atribuem essa importância ao trabalho dos ACS. Segundo relato da ACS B "só nos ouvem quando a gente grita, damos de loucas e [...] interrompemos alguma reunião ou consulta. A equipe funciona muito bem, quando a gente grita". Isso de certa maneira está na prescrição social do trabalho, afinal como a equipe vê a importância do papel da ACS perante tantos outros saberes socialmente reconhecidos, o do médico, o do enfermeiro e assim por diante. É preciso gritar para se fazer ouvir, esse é um aspecto de importância para o analista do trabalho, para sentirmos o papel social ocupado pelas ACS e seu trabalho neste contexto de reuniões formais e multidisciplinares. Nas reuniões que presenciamos, como pesquisadores, com todos os profissionais da USF e com as equipes de saúde, observamos que os médicos e enfermeiros se preocupam mais em discutir problemas específicos das suas atividades, do que em discutir problemas e possíveis soluções para a melhoria da gestão, pensando na saúde da população atendida pela USF. Há na equipe hierarquia de saberes, logo diferentes valores são atribuídos ao trabalho dos profissionais (Schwartz, 1995).

\section{Outras renormalizações, dramáticas do uso de si e a gestão do trabalho}

As renormalizações, escolhas e dramáticas dos usos de si nas atividades de trabalho das ACS da USF Ilha das Caieiras estão presentes em relatos anteriores, dada a dificuldade de se formalizar uma análise do trabalho destes profissionais sob o ponto de vista da atividade sem fazer emergir o "coengendramento" entre as normas antecedentes e o que as escapa no trabalho "vivo e em atividade" das ACS, ou seja, na gestão do seu trabalho no dia a dia. Algumas passagens que serão descritas retratam os desafios e as demandas dos ACS. Acompanhamos uma situação interessante a qual demanda usos de si na gestão do trabalho das ACS nesta USF. Trata-se do manuseio de medicamentos no caso de usuários idosos que não conseguem ler os nomes dos remédios e as receitas dos médicos, ou dos pacientes que não sabem ler - que são em número significativo no local escolhido para investigação. As ACS desenvolveram em conjunto uma estratégia singular para lidar com essa situação. Numa tentativa de garantir que os usuários utilizem os medicamentos corretos e nos horários prescritos pelos médicos, elas agiram conforme Durrive (2011, p.3), participando “ativamente 
a serviço de uns pelos outros". As agentes montaram pequenas caixinhas com tampas nas quais os medicamentos para cada usuário que demanda tais cuidados especiais são depositados. Na tampa da caixa, é colado um papel com as divisões do dia que indicam as refeições ou não, no caso de jejum. Cada fração do dia é indicada por uma figura que melhor a simboliza. Por exemplo, o café da manhã é simbolizado por uma xícara de café e pão, etc. Tais frações do dia são coloridas, cada uma com uma cor diferente, indicando que aquele medicamento deve ser tomado naquele horário. Ilustrando a situação, se um paciente deve tomar um medicamento no almoço e no jantar e a figura do almoço foi colorida em vermelho e a do jantar em verde, as cartelas do respectivo medicamento levam um pequeno pedaço de fita adesiva vermelha e outro pequeno pedaço de fita adesiva verde.

Essa estratégia foi cuidadosamente desenvolvida e personalizada para cada usuário que demanda cuidados especiais e dificuldades na administração de medicamentos. Segundo a ACS A, "antes os pacientes tomavam muitos remédios errados, [...] por isso muitos não apresentavam melhoras e outros pioravam o estado de saúde". E, complementa uma farmacêutica "isso também acontece porque muda muito o nome e a cor dos remédios que o SUS manda, num mês o remédio para pressão tem um nome $e$ as pílulas são azuis, no outro mês [...] tem outro nome e as pílulas são amarelas; confunde muito os pacientes". Mas todos são unânimes em afirmar que após a estratégia da utilização das caixinhas com desenhos coloridos acompanhadas de fitas adesivas nas cartelas de medicamentos, os problemas de posologia indevida diminuíram.

Esse relato ressalta usos de si por si feito pelas ACS na busca da estratégia de solução do problema para lidar com a prescrição para não alfabetizados, além de tornar evidente o espaço para autonomia de decisão desses profissionais lá onde os eventos e o não antecipável ocorrem e, a renormalização coletiva no modo de ação a que são lançadas diante das variabilidades emergentes nas suas atividades de trabalho, quando refletem, engenham e socializam o método - o saber fazer - num processo de recriação das normas (Schwartz, 1998, 2004c, 2007b; Rosa, 2001; Terssac e Maggi, 2004; Durrive, 2011).

\section{Considerações finais}

A proposta deste artigo foi fazer um recorte analítico de uma pesquisa que buscou desenvolver a análise dos processos de trabalho dos Agentes Comunitários de Saúde, sob o ponto de vista da atividade. Profissionais estes inseridos na concepção da Estratégia de Saúde da Família, que atuam na USF Ilha das Caieiras, a qual fornece serviços integrais de acompanhamento em saúde à população residente num complexo de cinco bairros residenciais e periféricos, denominado "Grande São Pedro" na região da baía noroeste de Vitória-ES.

Salientamos que as ACS, todas mulheres e residentes no mesmo território em que trabalham, são profissionais, mães, esposas, trabalhadoras que deixam seus filhos na escola e fazem o serviço de casa antes de ir para o trabalho. A maioria delas, há quase uma década atuando como ACS, admite que apesar das muitas dificuldades encontradas no trabalho, gosta de atuar naquela função por terem a possibilidade de almoçar em casa, e ver os filhos crescerem. Ou seja, elas têm vínculo com a comunidade e algumas características desse trabalho vão ao encontro dos valores prezados por essas trabalhadoras.

Observamos que as ACS participantes da pesquisa vivem e trabalham com as "dramáticas do uso de si”, buscando preservar a saúde e prevenir doenças da população da microárea de sua responsabilidade, muitas vezes sem o devido apoio da gestão local do SUS para preservar a sua própria saúde, expondo-se ao sol durante todo o dia.

Podemos dizer ainda que são profissionais que vivem e trabalham renormalizando o trabalho com o objetivo de levar à população residente a produção de saúde em uma perspectiva integrada e participativa, sendo centrais nesse processo e perspectiva de gestão da saúde; diferentemente do antigo conceito de saúde-doença centrado na figura do médico. Estão ao mesmo tempo lidando com usuários que dependem quase exclusivamente dos serviços de saúde do SUS, mas que muitas vezes não reconhecem a importância do trabalho dessas ACS na nova perspectiva de saúde integrada, ou seja, os usuários estão ainda inseridos na perspectiva sociocultural da doença e da cura. Muitos usuários só procuram saber a respeito 
de saúde quando estão doentes e precisam de vaga para exames especializados ou para internação nos hospitais da rede pública.

Por fim, entendemos que as ACS vivem e trabalham "no fio da navalha", pois representam na rede de trabalho em saúde - na perspectiva da ESF - a linha de frente do SUS para com os usuários, cabendo a elas realizar a triagem dos problemas do território abrangido pela microárea de sua responsabilidade e informar à sua equipe de saúde. Embora elas aleguem não ter a importância do seu trabalho reconhecida pelos profissionais colegas da equipe, por questão de valores conforme discutimos no item analítico deste artigo.

Entendemos que pudemos mostrar ser este um trabalho complexo e desafiador, marcado por muitas variabilidades que demandam convocações e usos de si, dos saberes da experiência e levam a um constante embate de valores e escolhas para a sua execução.

A complexidade do trabalhar e viver no local aqui exposta é de certa forma prescrita pelo MS. Sob o ponto de vista da gestão pública, o trabalhador local cuida melhor do seu território, no entanto, a pesquisa coloca em análise quão desafiador pode se tornar isso para os ACS, desafios estes singularizados ainda mais pelo território específico em que se inserem (Queirós e Lima, 2012). Um território singular que há três décadas era visto como "lugar de toda a pobreza", onde o lixo alimentou e serviu de solo e trabalho para a população, trazendo doenças e estigmas que a população supera aos poucos. Um território marcado pela falta de integração do poder público no que diz respeito a programas que envolvam as áreas de Educação, Saúde, Assistência Social, Segurança entre outras. Um território que as ACS ajudam a transformar, colocando em ação os princípios da ESF no exercício cotidiano dos seus trabalhos.

Como contribuição para desafios de pesquisa futuros, apontamos pesquisar por que as ACS somente são ouvidas quando "gritam" com os colegas da USF e, a importância de se estudar a relação da atividade de trabalho das ACS com a formação do gênero profissional.

\section{Referências}

ALVAREZ, D.; TELLES, A. L. Interfaces ergonomiaergologia: uma discussão sobre trabalho prescrito e normas antecedentes. In: FIGUEIREDO, M. et al. (Org.). Labirintos do trabalho: interrogações e olhares sobre o trabalho vivo. Rio de Janeiro: Dp\&A, 2004. p. 63-9o.

AMORIM, H. Trabalho imaterial: Marx e o debate contemporâneo. São Paulo: Annablume: Fapesp, 2009.

ANTUNES, R. Os sentidos do trabalho: ensaio sobre a afirmação e a negação do trabalho. São Paulo: Boitempo, 2000.

BENEVIDES DE BARROS, R. D. Grupo: a afirmação de um simulacro. Porto Alegre: UFRGS, 2007.

BRASIL. Ministério da Saúde. Guia prático da saúde da família. Brasília, DF, 2001a. Disponível em: <http://bvsms.saude.gov.br/bvs/publicacoes/ partes/guia_psf1.pdf $>$. Acesso em: 28 maio 2013.

BRASIL. Ministério da Saúde. Programa Saúde da Família. Brasília, DF, 20o1b. Disponível em: <http://bvsms.saude.gov.br/bvs/publicacoes/ pacso1.pdf $>$. Acesso em: 28 maio 2013.

CALADO, G. S. A inserção da equipe de saúde bucal no programa de saúde da família: principais avanços e desafios. 2002. Dissertação (Mestrado em Saúde Pública) - Escola Nacional de Saúde Pública, Rio de Janeiro, 2002.

CÁRITAS. Cáritas brasileira. São Paulo, 2008. Disponível em: <http://caritas.org.br/novo/>. Acesso em: 28 maio 2013.

CASTELLS, M. A sociedade em rede. São Paulo: Paz e Terra, 2007. (Era da Informação, Economia, Sociedade e Cultura, 1)

CORDEIRO, H. O desafio do ensino das profissões da saúde diante das mudanças do modelo assistencial: uma contribuição para além dos pólos de capacitação. Divulgação em Saúde para Debate, Rio de Janeiro, v. 21, n. 4, p. 36-43, 2000.

DEJOURS, C. O fator humano. Rio de Janeiro: FGV, 2003. 
DURRIVE, L. Caixa de ferramentas: o fio condutor do animador. In: ENCONTRO FRANCOBRASILEIRO DE ANÁLISE PLURIDISCIPLINAR DO TRABALHO, 1., 2001, Niterói. Livro de resumos... Niterói: Neict, 2001, p. 163.

DURRIVE, L. A atividade humana, simultaneamente intelectual e vital: esclarecimentos complementares de Pierre Pastré e Yves Schwartz. Trabalho, Educação e Saúde, Rio de Janeiro, v. 9, 2011. Suplemento 1.

FONSECA, T. M. G.; KIRST, P. G. (Org.). Cartografias e devires: a construção do presente. Porto Alegre: UFRGS, 2003.

GUÉRIN. F. et al. Compreender o trabalho para transformá-lo: a prática da ergonomia. São Paulo: Edgard Blücher: Fundação Vanzolini, 2004.

JAPIASSU, H.; MARCONDES, D. Dicionário básico de filosofia. Rio de Janeiro: Zahar, 1996.

LEPLAT, J. Aspectos da complexidade em ergonomia. In: DANIELLOU, F. (Coord.). A ergonomia em busca dos seus princípios: debates epistemológicos. São Paulo: Blücher, 2004. p. 33-44.

MARX, K. O Capital: livro I. Coimbra: Centelha, 1974.

QUEIRÓS, A. A. L.; LIMA, L. P. A

institucionalização do trabalho do agente comunitário de saúde. Trabalho, Educação e Saúde, Rio de Janeiro, v. 10, n. 2, p. 257-281, 2012.

ROLNIK, S. Cartografia sentimental: transformações contemporâneas do desejo. Porto Alegre: UFRGS: Sulina, 2006.

ROSA, M. I. Trabalho: nova modalidade de uso de si na educação: debates/confrontos de valores. In: ENCONTRO FRANCO-BRASILEIRO DE ANÁLISE PLURIDISCIPLINAR DO TRABALHO, 1., 2001, Niterói. Livro de resumos... Niterói: Neict, 2001, p. 213. SCHWARTZ, Y. Circulações, dramáticas, eficácias da atividade industriosa. In: BIDET, J; TEXIER, J. (Org.). La crise du travail. Paris: PUF, 1995. p. 21-38.
SCHWARTZ, Y. Os ingredientes da competência: um exercício necessário para uma questão insolúvel. Educação \& Sociedade, Campinas, v. 19, n. 65, p. 101-139, 1998.

SCHWARTZ, Y. Trabalho e uso de si. Pro-posições, Campinas, v. 1, n. 5, p. 27-52, 2000.

SCHWARTZ, Y. Seminário trabalho e saber. Belo Horizonte: UFMG, 2003.

SCHWARTZ, Y. Trabalho e gestão: níveis, critérios e instâncias. In: FIGUEIREDO, M. et al. (Org.). Labirintos do trabalho: interrogações e olhares sobre o trabalho vivo. Rio de Janeiro: Dp\&A, 2004a. p. 23-33.

SCHWARTZ, Y. Circulações, dramáticas, eficácias da atividade industriosa. Trabalho, Educação e Saúde, Rio de Janeiro, v. 2, n. 1, p. 33-55, 2004b.

SCHWARTZ, Y. Ergonomia, filosofia e exterritorialidade. In: DANIELLOU, F. (Coord.). A ergonomia em busca de seus princípios: debates epistemológicos. São Paulo: Edgard Blücher, 2004c. p. 141-18o.

SCHWARTZ, Y. Conceituando o trabalho, o visível e o invisível. Trabalho, Educação e Saúde, Rio de Janeiro, v. 9, p. 19-45, 2011. Suplemento 1.

SCHWARTZ, Y.; DURRIVE, L. (Org.). Trabalho \& Ergologia: conversas sobre a atividade humana. Rio de Janeiro: UFF, 2007.

TERSSAC, G. de; MAGGI, B. O trabalho e a abordagem ergonômica. In: DANIELLOU, F. (Coord.). A ergonomia em busca dos seus princípios: debates epistemológicos. São Paulo: Edgard Blüncher, 2004. p. 79-104.

VIANA, A. L. D’Á.; DAL POZ, M. R. A reforma do sistema de saúde no Brasil e o Programa de Saúde da Família. Physis: Revista de Saúde Coletiva, Rio de Janeiro, v. 8, n. 2, p. 11-48, 1998. 